\title{
Renal Transplantation in Patients with Aortoiliac Prosthetic Grafts: A Case Report and Pertinent Review of Literature
}

\author{
Sachin Patil', Harry Sun ${ }^{2}$, Stuart Geffner ${ }^{2}$, H. Stephen Fletcher ${ }^{1,2}$, Ronald S. Chamberlain 1,3,4* \\ ${ }^{1}$ Department of Surgery, Saint Barnabas Medical Center, Livingston, USA \\ ${ }^{2}$ Department of Transplant, Saint Barnabas Medical Center, Livingston, USA \\ ${ }^{3}$ Department of Surgery, Saint George's University School of Medicine, Saint George's, Grenada \\ ${ }^{4}$ Department of Surgery, Rutgers University, Newark, USA \\ Email: ${ }^{*}$ DChamberlain@Barnabashealth.org
}

Received 1 January 2015; accepted 20 January 2015; published 30 January 2015

Copyright (C) 2015 by authors and Scientific Research Publishing Inc.

This work is licensed under the Creative Commons Attribution International License (CC BY).

http://creativecommons.org/licenses/by/4.0/

(c) $\underset{\mathrm{EY}}{\mathrm{B}}$ Open Access

\begin{abstract}
Renal transplantation in a patient with aortoiliac prosthetic graft is a unique challenge. It requires that the renal artery is anastomosed directly to the vascular prosthetic graft. Nearly $0.2 \%-1.7 \%$ of the patients with aortoiliac prosthesis require renal transplantation in their life time. Outcomes following such procedure are controversial and anecdotal. In this report we present a unique case in which the renal artery was anastomosed to vascular prosthetic graft with a pertinent review of the literature.
\end{abstract}

Keywords

Aortoiliac Disease, Prosthesis, Renal Transplant

\section{Introduction}

The number of patients requiring renal transplantation with aortoiliac occlusive or aneurysmal disease is small; however this population is expected to rise with increasing recipients' age [1] [2]. Currently $0.2 \%-1.7 \%$ of patients with aortoiliac prosthesis require renal transplantation in their life time [3]-[6]. In the absence of uniform screening criteria for vascular diseases in renal transplant recipients, the majority of cases requiring aortoiliac reconstruction are diagnosed intra-operatively [2]. Renal transplantation in the presence of aortoiliac prosthesis often mandates direct anastomosis of the donor renal artery to the vascular prosthesis. In this report we present a

${ }^{*}$ Corresponding author.

How to cite this paper: Patil, S., Sun, H., Geffner, S., Fletcher, H.S. and Chamberlain, R.S. (2015) Renal Transplantation in Patients with Aortoiliac Prosthetic Grafts: A Case Report and Pertinent Review of Literature. Open Journal of Organ Transplant Surgery, 5, 1-5. http://dx.doi.org/10.4236/ojots.2015.51001 
unique case involving a 62-year male patient in whom the renal artery was anastomosed directly to an aorto-iliac bypass Dacron graft. A pertinent review of the literature with practice guidelines is also provided.

\section{Case Report}

A 62 years old Caucasian male with end stage renal disease secondary to renovascular disease was admitted to the renal transplant service for a deceased donor transplant on December 2011. He was a smoker with 35-packyear history of smoking, which he stopped in 1998. He had been dialysis dependent since 1996. His past medical history was significant for coronary artery disease, hypertension, hyperlipedemia, gout and hypothyroidism. His past surgical history included a cardiac catheterization and single vessel stenting (2003), followed by a two vessel coronary artery bypass grafting (2010). In addition he suffered from severe abdominal aorto-visceral atherosclerotic occlusive disease with superimposed thrombosis, and had undergone thrombo-endarterectomy and infra-renal aorto-iliac bypass graft in 1998. Computed tomography angiography done in 2010 revealed a patent aorto-iliac bypass graft, patent internal and external iliac arteries, with occlusion of bilateral renal arteries, as well as the native infra-renal aorta and common iliac arteries. The left limb of the graft extended beyond the left common iliac bifurcation. On admission he was well, except for requiring hemodialysis three times a week. He denied chest pain or claudication. Pertinent clinical examination revealed a patent left upper extremity arteriovenous fistula, palpable femoral, popliteal, dorsalis pedis and posterior tibial pulses with no signs of acute or chronic arterial insufficiency. Electrocardiogram revealed left bundle branch block and echocardiography demonstrated a normal left ventricular wall motion with an ejection fraction of 68\%. After appropriate institutional transplant review he was listed for deceased donor renal transplant with a plan to place the transplant on the right side, in view of the aorto-iliac graft extending beyond the left common iliac artery.

The donor kidney had two arteries, so a Carrel patch was benched on the back table. After accessing the right retroperitoneal space and the native right external iliac artery was examined and found to be completely calcified. At this point the decision was taken to anastomose the renal artery to common iliac limb of the aorto-iliac prosthetic graft. The renal vein was anastomosed in an end-to-side fashion to the common iliac vein. Following the venous anastomosis the Carrel patch was subsequently anastomosed in an end-to-side fashion to the prosthetic graft. The ureteroneocystostomy was performed to complete the procedure.

The postoperative recovery was uneventful, with excellent immediate kidney function and no vascular events. Renal transplant scintigraphy was performed using $5.3 \mathrm{mCi}$ of 99m Tc MAG-3 on post-operative day one, which revealed an intact arterial perfusion and homogeneous renal transplant nephrogram without any evidence of hydronephrosis or extravasation (Figure 1). Renal transplant ultrasound was obtained on post-operative day five, also revealed good arterial and venous flow, with no hydronephrosis (Figure 2). Excellent blood flow in both the right external iliac artery and vein was similarly appreciated (Figure 3(a) and Figure 3(b)). The postoperative course was uneventful the creatinine trended downwards and reached a baseline of $1.76 \mathrm{mg} / \mathrm{dl}$. The patient was discharged home in a stable condition on post-operative day nine. After thirty two months follow-up the transplanted kidney is working well (creatinine; $1.06 \mathrm{mg} / \mathrm{dl}$ ), without any signs or symptoms of vascular insufficiency in the right lower extremity.

\section{Discussion}

Renal failure patients are at a risk of accelerated atherosclerosis and arterial calcification compared to age matches controls. Patients with chronic renal failure (CRF) also suffer from a number of non-traditional cardiovascular risk factors related to the duration of dialysis and mineral metabolism, which are proposed to play a prominent role in the pathogenesis of arterial calcification [7]. Detailed discussion on pathogenesis and the role of those precursors is beyond the scope of this report, however these factors clearly increase the risk of arterial calcification 2- to 5-fold in CRF patients [8]. Increased arterial calcification has special implications in renal transplant recipients, especially when it occurs in the common iliacs, or the internal and the external iliac arteries, which are the potential sites for donor arterial anastomosis in a standard heterotrophic renal transplant. Traditionally, patients with severe and uniform calcifications of the iliac artery sector are excluded from renal transplant list, as at least $3 \mathrm{~cm}$ of disease free vessel is required to perform a satisfactory anastomosis [9]-[11]. In light of the fact some authors have recommended aortoiliac reconstruction as a bridge to renal transplantation in patients with severe calcification of iliac arteries [9] [12]. That said there is no uniform criteria set for the screening of arterial disease in potential transplant recipients, and in general a combination of doppler ultra- 


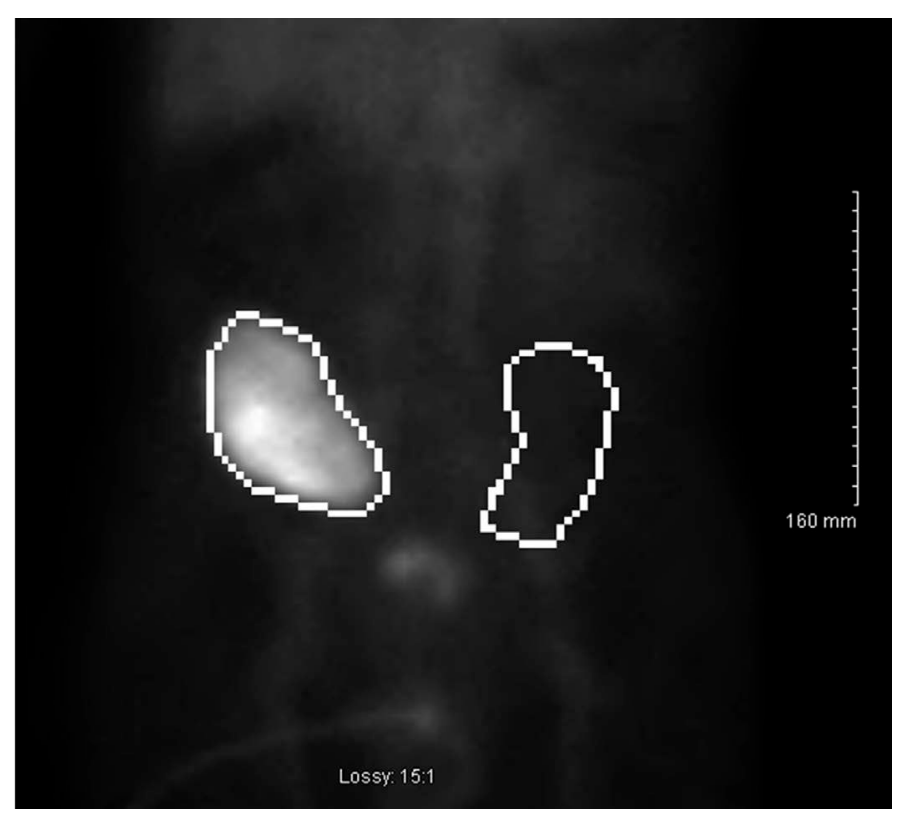

Figure 1. Renal transplant scintigraphy performed using $5.3 \mathrm{mCi}$ of 99m Tc MAG-3, demonstrating intact arterial perfusion and homogeneous renal transplant nephrogram without evidence of hydronephrosis or extravasation.

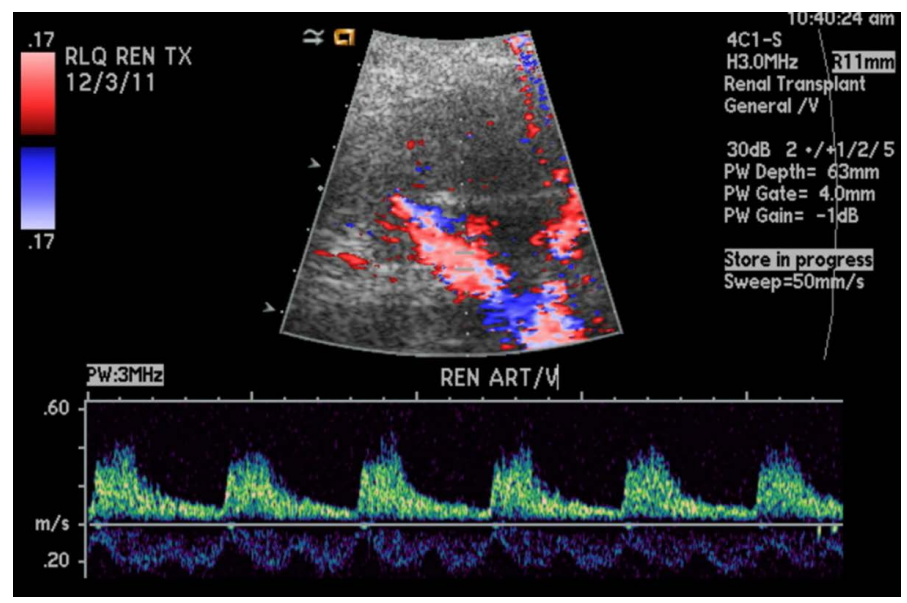

Figure 2. Renal transplant ultrasound demonstrating good arterial and venous flow.

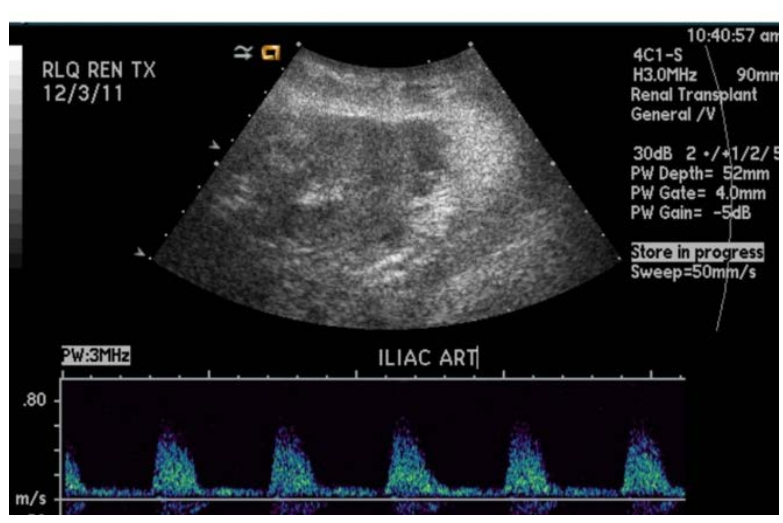

(a)

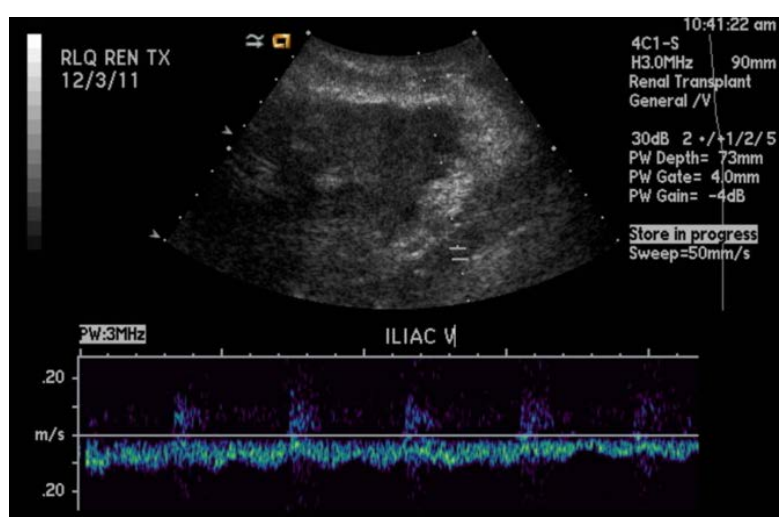

(b)

Figure 3. Post-renal transplant ultrasound demonstrating good blood flow to the external iliac artery and vein. 
sound (DOP-US) and helical computed tomography (CT) angiography are used in patients with claudication, previous vascular surgery, or in asymptomatic patients older than 60 years with vascular risk factors, bruits or asymmetric lower limbs pulses [13]. It is common practice in our own transplant program to evaluate for arterial disease using CT angiography in patients with a history of claudication and asymmetric peripheral vascular pulses in the lower extremities. The patient described in this report had undergone a CT angiography 18 months prior to renal transplant, at which time there was no evidence of calcification in the right common iliac or either external iliac artery. Despite this study, extensive calcifications were noted interestingly precluding direct arterial anastomosis, further highlighting the necessity for high risk renal transplant recipients to undergo vascular imaging every 6 - 12 months while on the transplant list [11].

Therapeutic options are limited in patients with severe calcification of iliac artery and include orthotropic renal transplant or aorta and/or femoral bypass procedures, with or without direct anastomosis of the transplant artery to the prosthetic graft [1] [2] [5] [9] [10]. In the majority of the instances in which sever aortoiliac disease is diagnosed intra-operatively during renal transplantation, anastomosis of renal artery to a vascular prosthetic graft posses a highly technical and unique challenge [2] [5]. Renal arterial anastomosis to a vascular prosthetic graft, was initially described by Sterioff et al. in 1974 and later by Ahlmen et al. Typically the case is not technically difficult except unless the iliac vein is scarred or fibrotic, in which case the renal vein can be anastomosed to inferior vena cava [1] [14] [15]. Coosemans et al. reported on 16 renal transplant recipients in whom renal artery anastomosis was performed directly to a vascular prosthesis either simultaneously or after vascular surgery procedure for aortoiliac disease. The authors reported no difference in 5-year patient survival or renal transplant graft survival when these patients were compared to outcomes among 978 age-matched renal transplant recipients with direct native arterial anastomosis [3]. In contrast to this report, van der Vliet et al. reported on 13 renal transplant patients in which the renal artery was anastomosed to vascular prosthetic graft and noted a high perioperative mortality of 15\%. Transplant and patient survival were 68\% and 83\% respectively at 1 year and $17 \%$ and $37 \%$ at 5 years. These authors concluded that anastomosis to a vascular graft is hazardous and associated with markedly diminished short- and long-term results, noting however that late mortality was mainly due to cardiovascular events [5]. In the current case we encountered no difficulty in creating the anastomosis between the renal artery and vascular prosthetic graft and after thirty two months of follow-up the transplanted kidney is functioning well.

As mentioned earlier, simultaneous aortoiliac reconstruction and renal transplantation is another option for patients with iliac artery sector calcification. Outcomes following simultaneous renal transplantation and aortoiliac surgery are controversial in the published literature, with increased aortoiliac graft infection rates, renal transplant failure and mortality as main concerns [1] [2] [5] [12] [16]. Small sample size from single institutions, diverse nature of aorto-iliac disease requiring reconstruction, and absence of randomization makes it difficult to compare published results across the literature. Tsivian et al. reported high early renal transplant loss rate (16.7\%) and a high early mortality rate (10\%) in patients 30 patients undergoing simultaneous aortoiliac reconstruction and renal transplantation [2]. Because of these concerns some surgeons suggested that aortoiliac reconstruction should precede renal transplantation by six to 12 weeks [4] [12] [17]. Several others found no significant increase in the prosthesis infection rates or graft failure rates in patients undergoing simultaneous aortoiliac reconstruction and renal transplantation [3] [4] [6]. Cooseman et al., compared 1761 renal transplants without vascular reconstruction (Group I) against 24 patients (Group II) who underwent aortoiliac reconstruction before $(\mathrm{N}=8)$, simultaneously with $(\mathrm{N}=8)$, or after renal transplantation $(\mathrm{N}=8)$. The authors noted that there was no significant difference in 1 year (Group 1: 92.6\%; Group II: 83.3\%) and 5 year (Group 1: 81.5\%; Group II: 73.5\%) actuarial survival between the groups, $p=0.06$. Similarly, there was no significant difference in the actuarial graft survival between the groups at 1 year (Group 1: 86.0\%; Group II: 83.3\%) and 5 years (Group 1: 71.9\%; Group II: 73.5\%), $p=0.6$ [3]. Further it may be argued that simultaneous procedures are associated with reduced risk of repeat anesthesia, easier post-operative fluid and electrolyte management, avoiding technical difficulties like dissection through perivascular fibrosis during re-operation, short hospitalization and reduced cost of care [3] [4] [6].

\section{Conclusion}

In conclusion renal transplantation can be safely performed in patients with aortoiliac disease with short-term good outcome; however long-term outcome remains controversial. Uniform screening criteria for calcific vascular disease of the iliac artery sector need to be set to avoid intraoperative surprises. 


\section{References}

[1] Pittaluga, P., Hassen-Khodja, R., Cassuto-Viguier, E., Batt, M., Declemy, S., Bariseel, H., Toubol, J. and Le, B.P. (1998) Aortoiliac Reconstruction and Kidney Transplantation: A Multicenter Study. Annals of Vascular Surgery, 12, 529-536. http://dx.doi.org/10.1007/s100169900196

[2] Tsivian, M., Neri, F., Nardo, B., Bertelli, R., Cavallari, G., Fuga, G. and Faenza, A. (2009) Aortoiliac Surgery Concomitant with Kidney Transplantation: A Single Center Experience. Clinical Transplantation, 23, 164-167. http://dx.doi.org/10.1111/j.1399-0012.2009.00981.x

[3] Coosemans, W., Nevelsteen, A., Pirenne, J. and Vanrenterghem, Y. (1999) Renal Transplantation in Patients with a Vascular Aortoiliac Prosthesis. Transplantation Proceedings, 31, 1925-1927. http://dx.doi.org/10.1016/S0041-1345(99)00207-9

[4] Gouny, P., Lenot, B., Decaix, B., Rondeau, E., Kitzis, M., Lacave, R., Bensenane, J. and Nussaume, O. (1991) Aortoiliac Surgery and Kidney Transplantation. Annals of Vascular Surgery, 5, 26-31. http://dx.doi.org/10.1007/BF02021773

[5] Van der Vliet, J.A., Naafs, D.B., Van Bockel, J.H., Kootstra, G., Boll, A.P., Barendregt, W.B. and Buskens, F.G. (1996) Fate of Renal Allografts Connected to Vascular Prostheses. Clinical Transplantation, 10, 199-202.

[6] Wright, J.G., Tesi, R.J., Massop, D.W., Henry, M.L., Durham, J.R., Ferguson, R.M. and Smead, W.L. (1991) Safety of Simultaneous Aortic Reconstruction and Renal Transplantation. American Journal of Surgery, 162, 126-130. http://dx.doi.org/10.1016/0002-9610(91)90173-B

[7] Moe, S.M. and Chen, N.X. (2004) Pathophysiology of Vascular Calcification in Chronic Kidney Disease. Circulation Research, 95, 560-567. http://dx.doi.org/10.1161/01.RES.0000141775.67189.98

[8] Schwarz, U., Buzello, M., Ritz, E., Stein, G., Raabe, G., Wiest, G., Mall, G. and Amann, K. (2000) Morphology of Coronary Atherosclerotic Lesions in Patients with End-Stage Renal Failure. Nephrology Dialysis Transplantation, 15, 218-223. http://dx.doi.org/10.1093/ndt/15.2.218

[9] Davins, M., Llagostera, S., Jimenez, R., Rosales, A., Romero, J.M. and Diaz, J.M. (2009) Aortofemoral Bypass to Bridge End-Stage Renal Disease Patients with Severee Iliac Calcification to Kidney Transplantation. Vascular, 17, 269-272. http://dx.doi.org/10.2310/6670.2009.00044

[10] Catala, V., Marti, T., Diaz, J.M., Cordeiro, E., Samaniego, J., Rosales, A. and De La Torre, P. (2010) Use of Multidetector CT in Presurgical Evaluation of Potential Kidney Transplant Recipients. Radiographics, 30, 517-531. http://dx.doi.org/10.1148/rg.302095080

[11] Andres, A., Revilla, Y., Ramos, A., Gonzalez, E., Vereda, M.S., Praga, M., Morales, E., Morales, J.M., Diaz, R., Cruceyra, G., Aguirre, F., Leiva, O. and Gragera, F. (2003) Helical Computed Tomography Angiography Is the Most Efficient Test to Assess Vascular Calcifications in the Iliac Arterial Sector in Renal Transplant Candidates. Transplantation Proceedings, 35, 1682-1683. http://dx.doi.org/10.1016/S0041-1345(03)00626-2

[12] Brekke, I.B., Lien, B., Sodal, G., Jakobsen, A., Bentdal, O., Pfeffer, P., Flatmark, A. and Fauchald, P. (1993) Aortoiliac Reconstruction in Preparation for Renal Transplantation. Transplant International, 6, 161-163. http://dx.doi.org/10.1111/j.1432-2277.1993.tb00638.x

[13] Burgos, F.J., Pascual, J., Marcen, R., Garcia-Navas, R., Gomez, V. and Ortuno, J. (2004) The Role of Imaging Techniques in Renal Transplantation. World Journal of Urology, 22, 399-404. http://dx.doi.org/10.1007/s00345-004-0412-1

[14] Sterioff Jr., S., Zachary, J.B. and Williams, G.M. (1974) Dacron Vascular Grafts in Renal Transplant Patients. American Journal of Surgery, 127, 525-528. http://dx.doi.org/10.1016/0002-9610(74)90310-9

[15] Ahlmen, J., Henriksson, C., Claes, G., Gelin, L.E. and Thoren, O. (1979) Successful Kidney Transplantation in a Man with Dacron “Trouser” Prosthesis. Scandinavian Journal of Urology and Nephrology, 13, 133-135. http://dx.doi.org/10.3109/00365597909180015

[16] Pampaloni, F., Sanchez, L.J., Bencini, L. and Taddei, G. (2002) Simultaneous Aortoiliac Reconstruction and Renal Transplantation: Is It Safe? Chirurgia Italiana, 54, 115-120.

[17] Piquet, P., Berland, Y., Coulange, C., Olmer, M., Mercier, C. and Rampal, M. (1989) Aortoiliac Reconstruction and Renal Transplantation: Staged or Simultaneous. Annals of Vascular Surgery, 3, 251-256. http://dx.doi.org/10.1016/S0890-5096(07)60034-X 
Scientific Research Publishing (SCIRP) is one of the largest Open Access journal publishers. It is currently publishing more than 200 open access, online, peer-reviewed journals covering a wide range of academic disciplines. SCIRP serves the worldwide academic communities and contributes to the progress and application of science with its publication.

Other selected journals from SCIRP are listed as below. Submit your manuscript to us via either submit@scirp.org or Online Submission Portal.
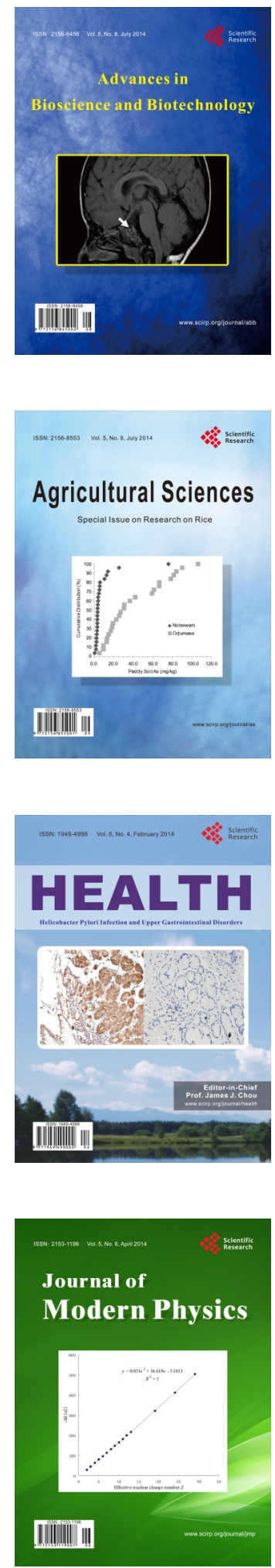
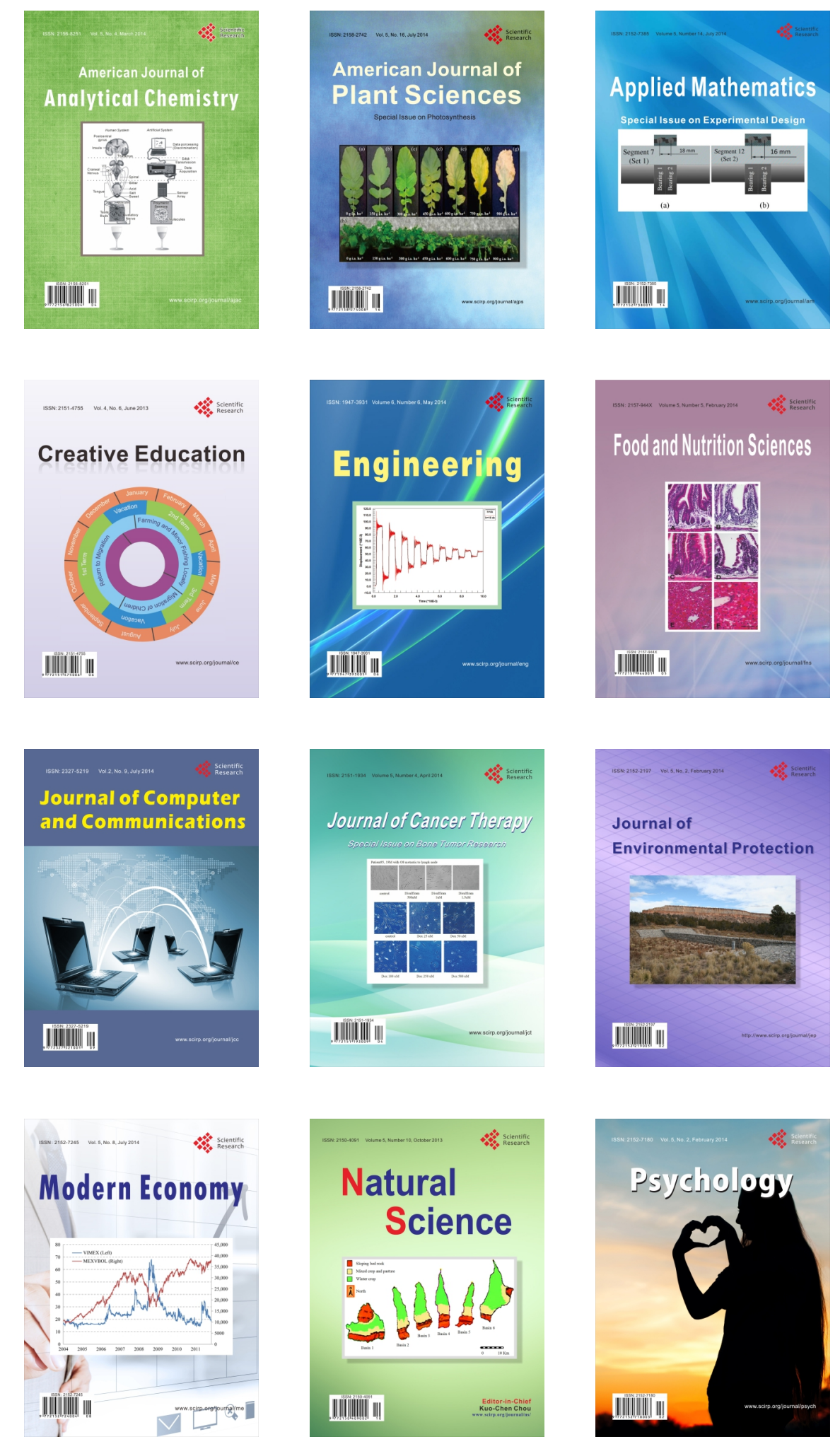